\title{
New Trends in Minimally Invasive Urological Surgery
}

\author{
Prabhakar Rajan, Burak Turna
}

Section of Surgery (PR), Division of Cancer Sciences and Molecular Pathology, University of Glasgow, United Kingdom, and Department of Urology (BT), Ege University School of Medicine, Izmir, Turkey

\begin{abstract}
Purpose: The perceived benefits of minimally-invasive surgery include less postoperative pain, shorter hospitalization, reduced morbidity and better cosmesis while maintaining diagnostic accuracy and therapeutic outcome. We review the new trends in minimally-invasive urological surgery.

Materials and Methods: We reviewed the English language literature using the National Library of Medicine database to identify the latest technological advances in minimally-invasive surgery with particular reference to urology.

Results: Amongst other advances, studies incorporating needlescopic surgery, laparoendoscopic single-site surgery, magnetic anchoring and guidance systems, natural orifice transluminal endoscopic surgery and flexible robots were considered of interest. The results from initial animal and human studies are also outlined.

Conclusion: Minimally-invasive surgery continues to evolve to meet the demands of the operators and patients. Many novel technologies are still in the testing phase, whilst others have entered clinical practice. Further evaluation is required to confirm the safety and efficacy of these techniques and validate the published reports.
\end{abstract}

Key words: urology; surgical procedures, minimally invasive; laparoscopy; robotics

Int Braz J Urol. 2009; 35: 514-20

\section{INTRODUCTION}

Minimally-invasive surgery (MIS) is a term that encompasses a variety of procedures that avoid open surgery in favor of closed or local procedures with less trauma. The definition of "minimally-invasive" is being constantly revised to include surgical techniques that allow reduced trauma, decreased morbidity, less postoperative pain, shorter hospital stay and better cosmetics in conjunction with comparable diagnostic accuracy and therapeutic outcome to open surgery. In the urological armamentarium, MIS involves endoscopy, laparoscopy and robotics to access the urinary tract and associated organs for diagnosis and treatment.
The laparoscopic renaissance began in the 1980s with laparoscopic cholecystectomy, but it was not until 1991 that Clayman et al. pioneered laparoscopic nephrectomy (1). Since then, MIS has undergone a technological revolution and is now commonplace in modern urological practice for a variety of diagnostic, ablative and reconstructive procedures.

Urological laparoscopy usually involves the use of several (3 to 6) trocars for tissue dissection, retraction, ablation and reconstruction. Efforts are on the horizon to further decrease associated surgical morbidity and improve aesthetic outcome. For example, small laparoscopes, trocars, and operative instruments minimize abdominal trauma and optimize cosmetic 
results. In this context, another approach, natural orifice transluminal endoscopic surgery (NOTES), endeavours to diminish treatment morbidity. This trend is clearly seen in the published urological literature. Despite the rapid increase in the number of publications in the field, there is a wide variation in terminology. For this reason, the Urologic NOTES Working Group has proposed that NOTES and laparoendosopic single-site surgery (LESS) be accepted as common terms in order to define these new procedures for better scientific communication (2).

In this review, we outline the recent advances in MIS in urology with a special emphasis on needlescopic surgery, LESS, NOTES, magnetic anchoring and guidance systems (MAGS) and flexible robots.

\section{NEEDLESCOPIC LAPAROSCOPY}

Needlescopic surgery (NS) is a refinement of laparoscopic surgery in which instruments and ports smaller than 3-mm in diameter are used as compared with standard 5-mm and 10-mm sizes used in conventional laparoscopy. NS was initially introduced for diagnostic purposes in gynecology, has since been used for several other procedures (3-6).

Controversy remains to whether or not all ports should be "needlescopic", or if a combination of sizes is acceptable. Clearly, in ablative procedures, there is no advantage in using a completely needlescopic technique and subsequently extending the incision to remove the specimen. The perceived advantages of NS include incisions, which do not require suturing, reduced wound complications, undetectable scars, reduced analgesia, reduced risk of incisional hernias, and faster recovery (5). The disadvantages of NS include loss of image quality through miniaturization of rod-lens scopes. Although more expensive fiber-optic scopes provide better image quality, these devices are fragile and visualization is often suboptimal for complex procedures. The 2-mm instruments lack tensile rigidity, and have weaker grasping capabilities. Thus, NS can be technically more demanding, resulting in longer operating times (5).

Soble and Gill have performed a number of NS procedures including adrenalectomy, nephrectomy, nephroureterectomy and exploration for cryptorchidism using a combination of needlescopic and standard ports (6). This group also reported shorter operative time, less blood loss, shorter hospital stay and convalescent period with needlescopic adrenalectomy as compared with laparoscopic adrenalectomy (7).

Despite several published reports using NS, data from randomized controlled trials are lacking in urology and studies in general surgery are not firmly conclusive $(5,8)$. Furthermore, the technical difficulties and lack of wider availability associated with NS and more recent technological advances have resulted in this technique failing to gain wider acceptance in the urological community. However, needlescopic instruments have recently been popularized again for additional instrumentation during reconstructive LESS procedures (9).

\section{LAPAROENDOSCOPIC SINGLE-SITE SURGERY (LESS)}

At present, most laparoscopic procedures are usually performed using at least 3 ports: one camera port and 2 or more instrument ports. Using novel instruments, LESS has emerged as another alternative to standard laparoscopy with lesser morbidity. Developments in instrument and port technology have facilitated multiple instruments to be inserted through a single port. Single port laparoscopic cholecystectomy and appendectomy have both been undertaken with the aid of a transabdominal stay sutures $(10,11)$.

Rane et al. presented a preliminary report in the urological field using a single port device for various urological procedures (12). Simple nephrectomy and transperitoneal ureterolithotomy have been performed by inserting a single 5-mm 30 degree telescope and two 5-mm working instruments using the R-Port ${ }^{\circledR}$ SPA system (Advanced Surgical Concepts, Dublin, Ireland). Desai et al. published an initial 2 cases of single port transumbilical nephrectomy and pyeloplasty using the R-Port $\AA$, inserted through a transumbilical incision (13). Novel, specialized instruments, curved at the shaft, were used. A 2-mm needle-port (MiniSite, USSC, Norfolk, CT, USA) was also inserted to facilitate suturing during single-port laparoscopic pyeloplasty. The same group has also described single-port laparoscopic donor nephrectomy 
and single-port laparoscopic partial nephrectomy using the R-Port ${ }^{\circledR}(14,15)$.

Kaouk et al. presented their experience with single-port laparoscopic urological surgery using the Uni-X Single Port Access Laparoscopic System (Pnavel Systems, Morganville, NJ, USA) in 14 patients, including radical prostatectomy in 4, renal cryotherapy in 4, wedge kidney biopsy in 1, radical nephrectomy in 1 , and abdominal sacrocolpopexy in 4 using the transperitoneal or retroperitoneal approach $(16,17)$. A $5 \mathrm{~mm}$ laparoscope with a flexible, steerable tip was employed (Olympus Surgical, Orangeburg, NY, USA). The authors completed all cases successfully without the need of conversion to a standard laparoscopic approach. Goel and Kaouk described a new technique during cryotherapy using the same single multi-channel port: Single Port Access Renal Cryoablation (SPARC) (18). The novel multi-channel single port was positioned in the umbilicus during the transperitoneal approach and at the tip of the 12th rib during the retroperitoneal approach in 6 patients. The authors reported the SPARC technique to be safe and feasible for small renal masses. Recently, Desai et al. presented the initial report of single-port transvesical enucleation of the prostate procedure for surgical treatment of large-volume benign prostatic hyperplasia (19).

Although flexible laparoscopic instruments allow parallel insertion through a single port, surgical range of motion is limited and "scissoring" of instruments is frequent. The transperitoneal approach offers virtually scarless surgery since the surgical incision is hidden in the umbilicus. A recent case-control comparison of 11 cases of single port nephrectomy with 22 cases of standard laparoscopic nephrectomy suggested that LESS is equally efficacious to standard laparoscopy (20). The cosmetic outcome of LESS is certainly promising, but further prospective studies are required to better define the role of LESS and fully evaluate the potential advantages of this novel technique over standard multi-port laparoscopy.

\section{NATURAL ORIFICE TRANSLUMINAL ENDOSCOPIC SURGERY (NOTES)}

A new and exciting development in MIS is NOTES. The principle of NOTES is to access the abdominal cavity via natural orifices without any incision in the abdominal wall. Although initial procedures have been performed via the transgastric route, the definition of NOTES includes other routes of access to the peritoneal cavity (21). These other sites are transvaginal, transvesical or transrectal. NOTES offers the possibility of "scar-free" surgery and could eliminate complications of traditional laparoscopy (e.g. abdominal wall pain, wound infection, incisional hernia) specifically in high-risk patient populations such as the critically-ill and the morbidly-obese.

The feasibility of natural orifice surgery was first demonstrated in 2002 by Gettman et al., who successfully performed transvaginal nephrectomy in a porcine model (22). Kaloo et al. first used the acronym NOTES in the literature when reporting on transgastric liver biopsies in a porcine model (23). A standard duodenoscope was advanced into the peritoneal cavity through a puncture in the gastric wall, which was later closed using standard surgical clips. Successful survival studies to prove the feasibility of NOTES also include tubal ligation, gastrojejunostomy, oophorectomy, cholecystectomy and partial hysterectomy in animal models. Several pioneering groups have undertaken NOTES procedures in humans after successful laboratory experience using transgastric (appendicectomy, liver biopsy, fallopian tube ligation, cholecystectomy, peritoneoscopy), transvaginal (cholecystectomy, peritoneoscopy), and transvesical (peritoneoscopy) approaches (24).

In view of the rapid development in this field, the Natural Orifice Surgery Consortium for Assessment and Research (NOSCAR) Working Group was formed to identify fundamental challenges to the safe introduction of NOTES in humans (21). Identified issues included peritoneal access, closure, prevention of infection, suturing, spatial orientation, development of stabilizing platform, and management of complications. Studies, thus far, have used different prophylactic antibiotic protocols and a variety of devices to close the visceral defect or allowed spontaneous closure.

Clayman et al. reported a trans-vaginal singleport "NOTES" nephrectomy in a non-survival porcine model (25). A single 12-mm port was sited in the midline, and a four-channel TransPort Multi-Lumen Operating Platform (USGI Medical, San Clemente, California, USA) was passed transvaginally. The renal 
artery and vein were obtained via the $12-\mathrm{mm}$ port and the kidney removed via the vagina in an EndoPouch retriever. Lima et al. used a combined transgastric and transvesical approach for nephrectomy in the porcine model (26). The renal vessels and ureter were ligated separately with ultrasonic scissors which were introduced through the transvesical port. Similarly, Isariyawongse et al. reported the feasibility of a pure NOTES nephrectomy using standard laparoscopic instruments through a modified transvaginal trocar in a porcine model (27). Transgastric visualization guided the introduction of a second transvaginal endoscope through a novel laparoscopic trocar. The Urology Working Group on NOTES was quickly formed by the pioneers in this field in order to address important aspects of NOTES and LESS in urology (28). The goals of the group was to define the nomenclature, increase awareness and training of NOTES, guide the scientific principles, and most importantly provide an outlet to share the discoveries in this field.

To date, no information is available on the perceived advantages of decreased postoperative pain, the risks of intra-abdominal sepsis due to iatrogenic visceral perforation or the long-term effects in humans. Other controversies include the possibility that NOTES may not be suitable in morbidly-obese, who may have increased intra-abdominal adipose tissue, and a blunted response to peritonitis. While both NOTES and LESS are considered "scarless surgery", NOTES requires specific instrumentation and expertise, conversion to standard laparoscopy is difficult, the abdominal access is indirect and the endoscopic perspective is different from standard laparoscopy.

In addition, the available instruments for NOTES have yet several limitations. However, despite this information gap, preliminary human assessments for urological surgery have already been conducted to evaluate the hybrid transvaginal NOTES nephrectomy for benign disease (29).

\section{MAGNETIC ANCHORING AND GUIDANCE SYSTEMS (MAGS)}

A significant limitation of standard laparoscopy is the conically-shaped fixed working area (envelope) of each port centered on the fulcrum at the trocar. The use of multiple ports improves intra-abdominal visibility and ergonomics, but can contribute to reduced cosmesis, postoperative pain, increased risk of bleeding and trocar-related intra-abdominal injury. Some of these issues are addressed by robotassisted surgery, which require multiple trocars, but is restricted by even smaller working envelopes and associated with hand-eye dissociation and lack of tactile perception.

A system of magnetically-anchored instruments for single-port laparoscopy has been recently developed (30). This consisted of external neodymium-iron-boron magnetic anchors, an internal camera system and a hook cautery supported by an intra-abdominal robotic arm. The system can be deployed through a single port and positioned by manipulating the external magnets. Two laparoscopic nephrectomies have been successfully completed in a non-survival porcine model without any complications (31). Based on their animal experience, Cadeddu et al. described their initial experience with MAGS during laparoscopic nephrectomy and appendectomy in 2 humans at the 2009 Annual Meeting of the American Urological Association (32).

\section{FLEXIBLE ROBOTS}

MIS requires certain psychomotor skills to cope with technological and procedural demands. Major obstacles include complexity of instrument controls, restricted vision and mobility, difficult handeye coordination, and the lack of tactile perception. Some of these issues are addressed by robotic surgery, which augments the surgeon's capabilities and facilitates task performances.

Multiple instruments simultaneously passing through natural orifices pose ergonomic difficulties and instruments must be flexible throughout their entirety to access the peritoneal cavity at any particular level. In addition, there are limitations as regards the control of the endoscopes, the endoscope tips, and instruments passed through the working channels. Recent research has focused on automation of endoscopy using flexible robotic devices.

Endoscopy works like a volumetric pump with the pushing action of the operator, being trans- 
lated into advancement of the tip, and torsional movement used to navigate bends. Automation requires locomotion and distal tip steering of the robot in the lumen. Using biologically-inspired technology, inchworm and other intelligent devices that "sense" surroundings have been designed (33) and tested in vitro in a porcine model for colonoscopy (34).

In vivo camera robots, unconstrained by the port position, can enhance intra-abdominal visualization. The efficacy of an in vivo camera robot was compared with a standard laparoscopic camera for simulated surgical tasks, and results demonstrated no significant difference in performance between the two systems (35). Using only a mobile in vivo camera robot for visual feedback, laparoscopic cholecystectomy has been successfully performed in the porcine model. The robot was inserted through a trocar into the abdominal cavity and allowed remote exploration of the cavity (36).

A second fixed-base-type in vivo robot has been designed with spring-loaded tripod legs, which can be folded during insertion through a traditional trocar (33). After insertion, the robot was positioned using traditional laparoscopic tools. Successful prostatectomy and nephrectomy have been undertaken using video feedback from both this camera system and a laparoscope in an animal model.

A novel remotely-controlled robotic catheter device (Hansen Medical System, Mountain View, CA, USA) has been successfully used to evaluate 7 patients presenting for mapping and/or ablation of atrial arrhythmia (37). This device enables the clinician to remotely position and maneuver a catheter tip. An adaptation of the system was used to successfully carry out flexible ureterorenoscopy and holmium laser lithotripsy in the porcine model (38). The authors reported the potential advantages of the novel robotic system to have increased range of motion, instrument stability, and improved ergonomics compared with conventional manual flexible ureterorenoscopy.

Recently, NOTES has been performed in a porcine model by an endoluminal robot capable of transgastric abdominal exploration (39). Under endoscopic control, a gastrotomy was created, and the robot was deployed into the peritoneal cavity. A helical wheel design provided traction for mobility while causing no observable tissue damage.

\section{GENERAL COMMENTS}

The enthusiasm for MIS is evident through the number of recent reports published in the literature. In urological surgery, preliminary data suggests that NS can provide promising results. Improvement of 2-mm instrumentation and optical technology is warranted. LESS provides a further advance towards a "scar-free" procedure, and outcomes from initial studies are promising. Regarding ablative procedures, a single incision will need to be extended to remove the specimen transabdominally, although this is possible via natural orifices.

The urologist's home territory in urinary tract endoscopy is undoubtedly advantageous to the development of NOTES in urology. However, the perceived benefits and safety considerations need to be conclusively demonstrated in survival animal studies and translated into clinical studies before NOTES is universally accepted. NOSCAR has issued guidelines on the safe pursuit of NOTES to avoid complications associate with premature adoption of the technique. Moreover, the recently formed Urology Working Group on NOTES is committed to safely and systematically implement NOTES in urology.

LESS, NOTES and flexible robots challenge the basic principle of MIS. Endoscopic views with NOTES differ from standard laparoscopy, and specialized instruments are required as standard instruments and endoscopes are too flexible to provide robust grasping and retraction. Unlike NOTES, specific expertise is not required for LESS, however, ergonomic triangulation, Azimuth and manipulation angles cannot be achieved using standard instrumentation through a single port. MAGS may facilitate intracorporeal instrument manipulation without the constraints of standard laparoscopy and robot-assisted surgery.

Remotely-controlled robotic catheter devices facilitate precise scope-tip positioning, improved ergonomics, and reduced radiation exposure in urological procedures. Multiple endoluminal and intraperitoneal robotic devices may enhance visualization and allow performance of complex tasks. Application of these technologies to flexible endoscopy and laparoscopy will allow the surgeon to have better control of instruments deployed through a natural orifice, and may 
even prove more cost-effective than robot-assisted surgery.

\section{CONCLUSIONS}

MIS continues to evolve to meet the demands of the pioneering operators and patients. Many novel technologies are still in the testing phase, whilst others have entered clinical practice. With further improvements in technology, minimally-invasive procedures under the combinatorial control of multiple devices on a single stable platform could become the preferred approach for the management of certain diseases in select patients. The safety, efficacy and clinical benefit will need to be clearly demonstrated whether these currently technically-demanding procedures are to be universally accepted. Until then, they will remain the domain of the experienced and pioneering laparoscopist.

\section{CONFLICT OF INTEREST}

None declared.

\section{REFERENCES}

1. Clayman RV, Kavoussi LR, Soper NJ, Dierks SM, Meretyk S, Darcy MD, et al.: Laparoscopic nephrectomy: initial case report. J Urol. 1991; 146: 278-82.

2. Box G, Averch T, Cadeddu J, Cherullo E, Clayman $\mathrm{R}$, Desai M, et al.: Nomenclature of natural orifice translumenal endoscopic surgery (NOTES) and laparoendoscopic single-site surgery (LESS) procedures in urology. J Endourol. 2008; 22: 2575-81.

3. Faber BM, Coddington CC 3rd: Microlaparoscopy: a comparative study of diagnostic accuracy. Fertil Steril. 1997; 67: 952-4.

4. Gagner M, Garcia-Ruiz A: Technical aspects of minimally invasive abdominal surgery performed with needlescopic instruments. Surg Laparosc Endosc. 1998; 8: 171-9.

5. Lau DH, Yau KK, Chung CC, Leung FC, Tai YP, Li MK: Comparison of needlescopic appendectomy versus conventional laparoscopic appendectomy: a randomized controlled trial. Surg Laparosc Endosc Percutan Tech. 2005; 15: 75-9.
6. Soble JJ, Gill IS: Needlescopic urology: incorporating 2-mm instruments in laparoscopic surgery. Urology. 1998; 52: 187-94.

7. Gill IS, Soble JJ, Sung GT, Winfield HN, Bravo EL, Novick AC: Needlescopic adrenalectomy--the initial series: comparison with conventional laparoscopic adrenalectomy. Urology. 1998; 52: 180-6.

8. Hosono S, Osaka H: Minilaparoscopic versus conventional laparoscopic cholecystectomy: a meta-analysis of randomized controlled trials. J Laparoendosc Adv Surg Tech A. 2007; 17: 191-9.

9. Desai MM, Stein R, Rao P, Canes D, Aron M, Rao PP, et al.: Embryonic natural orifice transumbilical endoscopic surgery (E-NOTES) for advanced reconstruction: initial experience. Urology. 2009; 73: 182-7.

10. Ates O, Hakgüder G, Olguner M, Akgür FM: Singleport laparoscopic appendectomy conducted intracorporeally with the aid of a transabdominal sling suture. J Pediatr Surg. 2007; 42: 1071-4.

11. Piskun G, Rajpal S: Transumbilical laparoscopic cholecystectomy utilizes no incisions outside the umbilicus. J Laparoendosc Adv Surg Tech A. 1999; 9: 361-4.

12. Rane A, Kommu S, Eddy B, Bonadio F, Rao P, Rao $P$ : Clinical evaluation of a novel laparoscopic port (R-Port $\left.{ }^{\circledR}\right)$ and evolution of the single laparoscopic port procedure (SLIPP). J Endourol. 2007; 21: A22. Abstract \# BR6-1.

13. Desai MM, Rao PP, Aron M, Pascal-Haber G, Desai MR, Mishra S, et al.: Scarless single port transumbilical nephrectomy and pyeloplasty: first clinical report. BJU Int. 2008; 101: 83-8.

14. Gill IS, Canes D, Aron M, Haber GP, Goldfarb DA, Flechner S, et al.: Single port transumbilical (ENOTES) donor nephrectomy. J Urol. 2008; 180: 63741; discussion 641.

15. Aron M, Canes D, Desai MM, Haber GP, Kaouk JH, Gill IS: Transumbilical single-port laparoscopic partial nephrectomy. BJU Int. 2009; 103: 516-21.

16. Kaouk JH, Goel RK, Haber GP, Crouzet S, Desai MM, Gill IS: Single-port laparoscopic radical prostatectomy. Urology. 2008; 72: 1190-3.

17. Kaouk JH, Haber GP, Goel RK, Desai MM, Aron M, Rackley RR, et al.: Single-port laparoscopic surgery in urology: initial experience. Urology. 2008; 71: 3-6.

18. Goel RK, Kaouk JH: Single port access renal cryoablation (SPARC): a new approach. Eur Urol. 2008; 53: 1204-9.

19. Desai MM, Aron M, Canes D, Fareed K, Carmona O, Haber GP, et al.: Single-port transvesical simple 
prostatectomy: initial clinical report. Urology. 2008; 72: 960-5.

20. Raman JD, Bagrodia A, Cadeddu JA: Single-Incision, Umbilical Laparoscopic versus Conventional Laparoscopic Nephrectomy: A Comparison of Perioperative Outcomes and Short-Term Measures of Convalescence. Eur Urol. 2008; 13. [Epub ahead of print]

21. Rattner D, Kalloo A; ASGE/SAGES Working Group: ASGE/SAGES Working Group on Natural Orifice Translumenal Endoscopic Surgery. October 2005. Surg Endosc. 2006; 20: 329-33.

22. Gettman MT, Lotan Y, Napper CA, Cadeddu JA: Transvaginal laparoscopic nephrectomy: development and feasibility in the porcine model. Urology. 2002; 59: 446-50.

23. Kalloo AN, Singh VK, Jagannath SB, Niiyama H, Hill SL, Vaughn CA, et al.: Flexible transgastric peritoneoscopy: a novel approach to diagnostic and therapeutic interventions in the peritoneal cavity. Gastrointest Endosc. 2004; 60: 114-7.

24. Swain P: Nephrectomy and natural orifice translumenal endoscopy (NOTES): transvaginal, transgastric, transrectal, and transvesical approaches. J Endourol. 2008; 22: 811-8.

25. Clayman RV, Box GN, Abraham JB, Lee HJ, Deane LA, Sargent ER, et al.: Rapid communication: transvaginal single-port NOTES nephrectomy: initial laboratory experience. J Endourol. 2007; 21: 640-4.

26. Lima E, Rolanda C, Pêgo JM, Henriques-Coelho T, Silva $\mathrm{D}$, Osório $\mathrm{L}$, et al.: Third-generation nephrectomy by natural orifice transluminal endoscopic surgery. J Urol. 2007; 178: 2648-54.

27. Isariyawongse JP, McGee MF, Rosen MJ, Cherullo EE, Ponsky LE: Pure natural orifice transluminal endoscopic surgery (NOTES) nephrectomy using standard laparoscopic instruments in the porcine model. J Endourol. 2008; 22: 1087-91.

28. Gettman MT, Box G, Averch T, Cadeddu JA, Cherullo E, Clayman RV, et al.: Consensus statement on natural orifice transluminal endoscopic surgery and singleincision laparoscopic surgery: heralding a new era in urology? Eur Urol. 2008; 53: 1117-20.

29. Branco AW, Branco Filho AJ, Kondo W, Noda RW, Kawahara N, Camargo AA, et al.: Hybrid transvaginal nephrectomy. Eur Urol. 2008; 53: 1290-4.

30. Park S, Bergs RA, Eberhart R, Baker L, Fernandez R, Cadeddu JA: Trocar-less instrumentation for laparoscopy: magnetic positioning of intra-abdominal camera and retractor. Ann Surg. 2007; 245: 379-84.

31. Zeltser IS, Bergs R, Fernandez R, Baker L, Eberhart R, Cadeddu JA: Single trocar laparoscopic nephrectomy using magnetic anchoring and guidance system in the porcine model. J Urol. 2007; 178: 288-91.

32. Cadeddu JA, Fernandez R, Desai MM, Bergs R, Tracy CR, Tang S-J et al.: Novel magnetically guided intraabdominal camera to facilitate laparoendoscopic single site surgery: initial human experience. J Urol. 2009; 181: (suppl. 4): 316. Abstract \# 886.

33. Rentschler ME, Oleynikov D: Recent in vivo surgical robot and mechanism developments. Surg Endosc. 2007; 21: 1477-81.

34. Guozheng Y, Kundong W, Jian S: Research on micro robot for colonoscopy. Conf Proc IEEE Eng Med Biol Soc. 2005; 5: 5050-3.

35. Strong VE, Hogle NJ, Fowler DL: Efficacy of novel robotic camera vs a standard laparoscopic camera. Surg Innov. 2005; 12: 315-8.

36. Rentschler ME, Dumpert J, Platt SR, Ahmed SI, Farritor SM, Oleynikov D: Mobile in vivo camera robots provide sole visual feedback for abdominal exploration and cholecystectomy. Surg Endosc. 2006; 20: 135-8.

37. Saliba W, Cummings JE, Oh S, Zhang Y, Mazgalev TN, Schweikert RA, et al.: Novel robotic catheter remote control system: feasibility and safety of transseptal puncture and endocardial catheter navigation. J Cardiovasc Electrophysiol. 2006; 17: 1102-5.

38. Desai MM, Aron M, Gill IS, Pascal-Haber G, Ukimura $\mathrm{O}$, Kaouk JH, et al.: Flexible robotic retrograde renoscopy: description of novel robotic device and preliminary laboratory experience. Urology. 2008; 72 : 42-6.

39. Rentschler ME, Dumpert J, Platt SR, Farritor SM, Oleynikov D: Natural orifice surgery with an endoluminal mobile robot. Surg Endosc. 2007; 21: 1212-5.

Accepted after revision:

May 13, 2009

\section{Correspondence address:}

Dr. Burak Turna

Department of Urology

Ege University School of Medicine

Bornova 35100, Izmir, Turkey

E-mail: burakturna@gmail.com 